with destruction of tissues followed by repair. On Jan. 16th the scar was excellent, but on June 22nd there was recurrence at the circumference of the lesions. On the other side, after ten injections there was no visible reaction, but a fading, then disappearance of the patches ; this was followed by the formation of a "whitish scarry tint." On June 22nd there was no sign of recurrence. But the authors admit that this observation requires to be confirmed by further experience. I have treated several cases in which old patches have been left after other treatments have failed. I have applied radium for periods of 15 minutes at a time, lightly screened with aluminium only. The results have been satisfactory. Certain obstinate cases are benefited by ionisation with zinc or copper.

To sum up: the object aimed at in using these agents is to set up a certain amount of local reaction. Hence they should never be used when there is acute inflammation. At present there are no rules to guide us in the selection of the particular agent; one will succeed where another fails. They must therefore be used more or less empirically.

Harley-street, W.

\section{A STUDY OF SPINAL AN ESTHESIA IN CHILDREN AND INFANTS.}

From a Series of 200 Cases.

By H. TYRRELL GRAY, M.A., M.C. CANTAB., F.R.O.S. ENG.,

RESIDENT MEDICAL SUPERINTENDENT, HOSPITAL FOR SICK CHILDREN, GREAT' ORMOND-STREET, LONOON.

SincE Bier in 1898 introduced spinal anæsthesia to the notice of the profession the subject has attracted considerable attention, especially on the continent, and more recently in this country. The technical methods have been greatly improved, and systematic study together with wider experience have increased the safety of the procedure. The relative value of spinal and general anæsthesia is still sub judice, though, from a theoretical aspect, the former is distinctly to be preferred in cases where it is applicable; for in the administration of spinal anæsthesia more of the nervous system is exempt from unnecessary paralysis, and there should be no involvement of the higher centres. In actual practice, while the younger method possesses undeniable and important advantages over general anæsthesia there are disadvantages in its application which will only be eliminated by a careful study of the principles on which depends the action of the drugs employed in the spinal theca. The safety of spinal anæsthesia seems to me to rest largely on the extent to which the surgeon can contro $\vec{i}$ and limit the action of the drugs employed. In this respect Mr. A. E. Barker's ${ }^{1}$ methods are a great advance on those employed on the continent, for he has made a definite attempt to place the localisation of the anæsthesia in the hands of the surgeon by the employment of gravity, and it is this opinion which led me to adopt his methods in my first 100 cases.

Though spinal anæsthesia has been administered to children in isolated cases a systematic study of its effects on children and infants has not hitherto been made so far as I am aware Deetz in Bier's clinic has had some success, while Preleitne in Professor Escherich's clinic ${ }^{2}$ reports a trial of the method in 40 children. The experience at the latter clinic does not seem to have been very encouraging. There seems to be a general impression that children are bad subjects for spinal anesthesia. Professor Fraenkel, speaking in the discussion on Preleitner's paper, ${ }^{3}$ emphasises the fact that in this method there was no elimination of the psychical factors tending to frighten the child and of the dread of the unpleasant situation, and that for this reason the method had already failed to obtain a foothold in the surgery of children. Other speakers also emphasised the satisfactory effects of general anæsthesia in children in whom, for this reason, spinal anæsthesia was, in their opinion, contra-indicated. Mr. Barker also states ${ }^{4}$ that this method should not be

1 B.

Brit, Med. Jour, March 23rd, 1907; and Feb. 1st and August 22nd,

2 Münchener Medicinische Wochenschrift, vol. lii., 1905, p. 1368$$
3 \text { Loc. cit. }
$$

4 Brit. Med. Jour., March 23rd, 1907 employed in obviously nervous and excitable people or in huldren.

These views are entirely contradicted by my experience. From the psychical aspect no more suitable patients for spinal anæsthesia could be found, since ignorance is their safeguard against "panic," and it may be stated generally that the younger the children the more satisfactory are they in this respect. Exception may perhaps be made to this statement in the case of children between the ages of two and five years; it is at this age that trouble is most likely to be experienced in keeping the patient quiet, though in the whole series of 200 cases on one occasion only did I encounter this difficulty to any marked extent. In no instance was general anæsthesia resorted to on this account. Further, statements as to the satisfactory nature of general anæsthesia in children require qualification : for there are many operations-notably on the abdomen, bones, and the larger jointsthe ultimate results of which, from their length and severity, have been greatly prejudiced by the additional strain and unpleasant sequelæ of general anæsthesia. It is in such cases that spinal anæsthesia is to be specially recommended. In the whole series there has been no selection of cases spinal anæsthesia has been administered whenever the method was applicable, with a view to ascertaining indications or contra-indications for its use.

\section{I.-A Study of the First Series of 100 Cases.}

I have been personally responsible for the anæsthesia in every case reported, and Mr. Barker's stovaine-glucose solution was used throughout this series. The composition of the fluid is : Stovaine, $2 \frac{1}{2}$ per cent.; glucose, $2 \frac{1}{2}$ per cent.; and water to 100.

Teshnique.-A very great deal has been written about the technique of puncture and injection of the fluid, and numerous rules have been laid down as essential to success. As regards the lumbar puncture, very many authors have devoted pages to laying stress upon the necessity of keeping the needle straight and entering it exactly in the middle line. These rules are modelled on the precepts laid down by Bier $^{5}$ and Donitz. ${ }^{6}$ I find, however, in a paper by Bier and Donitz ${ }^{7}$ that at this time they entered the needle one centimetre from the mid-line, directing it upwards and inwards, a custom which apparently they no longer follow. The dangers of puncturing in other than the mid-line are stated to be that of wounding the nerves of the cauda equina, hæmorrhage, and, if lumbar anæsthesia is the object, unilateral effects from the needle or cannula penetrating amongst the nerve-roots of one side. Kronig ${ }^{8}$ states that it is only after lateral puncture that cases of nervous affection due to injury of the nerve fibres are observed.

These dangers have, I am convinced, been greatly exaggerated, and in many accounts a simple procedure, easily carried out with the most ordinary care, has been converted into a major operation requiring special skill and practice. In some hundreds of lumbar punctures done for various objects on patients of all ages (most of these have, however, been on children) I have invariably adopted the same procedure. The site for puncture is chosen by placing the left forefinger between the two spinous processes at the level selected; the needle is then entered so that its shaft is just touching the pulp of the indicating finger (i.e., to one side of the spinous processes) and directed very slightly upwards and inwards. The needle is pushed smartly inwards, and in its course can be felt to penetrate two resistances: (1) the ligamentum subflarum; and (2) the dura mater. The stilette is withdrawn and a free flow of fluid practically always results then or on slightly rotating the needle.

By this means the needle, though entered laterally in the skin, punctures the dura in the midline. It has been a very unusual experience to see blood issuing from the needle, while the nerves have been touched by the needle or cannula on three occasions; once while performing a lumbar puncture on a man who had fractured the base of the skull, when respiration ceased for a considerable time, a phenomenon which could be reproduced by a suitable movement of the needle. The other two occasions when this accident occurred were in administering spinal anæsthesia to two children. In

5 Bier: Centralblatt für Chirurgie, vol. xxxiv., 1907, p. 95. 6 Donitz : Ibid., and vol. xxxiii., 1906, p. 105.

7 Bier and Donitz: Minchener Medicinische Wochenschrift, vol. li., 1904, pp. 593-596. 
both instances the child gave a piercing yell and became rigid and the course of the pain followed accurately the distribution of a spinal nerve. Neither of these children developed any unpleasant sequelæ and the anæsthesia in both was bilateral and perfectly satisfactory. Clearly, then, in my experience, this accident has been rare, and I think it has too often been made a scapegoat for unpleasant sequelæ without sufficient evidence.

The following is the routine which has been most successful. The patient is laid on the table on his right side with the back well rounded, and this position is maintained by the sister or nurse who is most familiar with the child and whom he trusts. This latter precaution makes a considerable difference to a child's behaviour in routine operations, while in cases of emergency no trouble is ever experienced. The whole back is cleansed, in the event of a second injection being necessary, and the child is placed on a sterile towel. Since the skin is the only sensitive structure encountered in a well directed puncture, it is first rendered anæsthetic by a hypodermic injection of eucaine 3 per cent. ( 20 minims). There is rarely any disturbance from the prick of a very fine needle. The instruments for injecting the stovaine are those designed by Mr. Barker, who has given full directions for their use. ${ }^{9}$

The lumbar puncture is now made in the manner already described; the cannula, affixed to the syringe, is gently pushed down the hollow needle (it is most essential that the depth of the needle should be kept constant), the injection given quickly, and the needle as quickly withdrawn. (It is a matter of no importance whether the injection is given forcibly or gently.) The child is then turned over on his back on to the sterile towel and the pelvis raised on a pillow to a height proportionate to the required level of anæsthesia. The majority of children will hardly be aware that the second or lumbar puncture has been made. In older children it is best to explain what is about to be done, especially if they are of a nervous disposition. The advantages of entering the needle to one side of the spinous processes are sufficiently marked to justify the procedure. In the first place speed is all-important in the case of children, in whom the resulting disturbance is in inverse proportion to the rapidity with which the injection is made.

Lateral puncture-(1) gives more room and so simplifies and hastens the procedure; (2) protects the needle against snapping or bending if the child should suddenly extend the spine ; and (3) diminishes the possibility of touching the sensitive periosteum of the lamina and thus causing pain and disturbance at the time and pain after the operation.

The preparation of the operation area is commenced directly the injection has been made, and when this is complete the operation may be begun. The child's face is covered with a towel so arranged that he can see the sister who holds his hands and amuses him. Many children are given a sponge cake or a bottle according to their age and may thus be kept quiet and happy during the operation. It is generally agreed that the injection of stovaine should not be made until a free flow of cerebro-spinal fluid has been obtained from the needle, and that if the fluid is bloodstained the dose should be withheld, ${ }^{10}$ for a satisfactory anæsthesia will not result. This is true enough in the main but if, after patience and perseverance, a free flow of fluid cannot be obtained, but only slow drops (or if slightly bloodstained fluid only appears) I consider that the injection should be attempted before making another puncture provided cerebro-spinal fluid has been seen. I have encountered this class of case on two or three occasions, when, in spite of failure to obtain a free jet, a perfectly satisfactory anæsthesia has resulted from the injection. I have concluded, therefore, that in isolated cases it will not be possible to get a free flow of cerebro-spinal fluid, though these will rarely be met with. Donitz ${ }^{11}$ suggests that when, in spite of all efforts, a scanty flow of cerebro-spinal fluid is obtained, this is an indication for using a larger bulk of fluid for injection. Mr. H. P. Dean ${ }^{12}$ is of the same opinion, and increases the bulk of fluid by adding saline solution.

Age. - In this series the age of the children has varied

9 Vide supra.

10 Bier and Donitz: Munchener Medicinische Wochenschrift, vol. li. 1904, pp. 593-596. Centralblatt für Chirurgie, vol. xxxiv., 1907, p. 94 .

Kronig: Loc. cit. pp. $525-548$

12 Brit. Med. Jour., 1907, vol. ii. considerably, the youngest being an infant aged three months, and the oldest a girl aged 13 years.

TABLE I.-Operations.

\begin{tabular}{|c|c|c|c|c|c|c|c|c|c|c|}
\hline nder 6 mon & & & & & & $\cdots$ & $\cdots$ & & & ses. \\
\hline 6 months to & year & & $\ldots$ & $\ldots$ & • & & & $\cdots$ & 8 & , \\
\hline 1 to 2 years. & $\cdots$ & $\cdots$ & $\cdots$ & $\cdots$ & $\cdots$ & $\cdots$ & $\cdots$ & $\cdots$ & 12 & " \\
\hline$" \quad \ldots$ & $\ldots$ & ... & $\ldots$ & $\ldots$ & ... & $\ldots$ & ... & ... & 25 & ," \\
\hline 5 to $12,, \ldots$ & $\cdots$ & $\ldots$ & .. & $\ldots$ & $\ldots$ & $\ldots$ & $\ldots$ & $\ldots$ & 49 & $"$ \\
\hline
\end{tabular}

It will be seen by the foregoing table that there were 25 cases in infants under 2 years, 25 cases from 2 to 5 years, and 49 cases from 5 to 12 years. The one child aged 13 years was not a patient at the Hospital for Sick Children, and spinal anæsthesia was administered to her owing to the prolonged vomiting which hitherto had followed general anæsthesia, and with infinitely more satisfactory results.

Nature of operations performed.-Of the operations performed 60 were on the trunk and 40 on the extremities (see Table II.). It will be seen that there were four instances where I failed to obtain any anæsthesia at all.

\section{TABLE II.-Nature of Operations.}

Operations on trunk :-

Abdominal, various

Appendicectomy...

Cystoscopy

Hernia and hydrocele (radical cure) ...

Hernia, strangulated

Intussusception ...

Ileocolostomy

Psoas and iliac abscess

Rectovaginal fistula

Sigmoidoscopy ..

Various

$$
\begin{aligned}
& 3 \text { cases. } \\
& 3 \text {, } \\
& 3 \text {, } \\
& 33 \\
& 3 \text {, } \\
& 5 \text {, } \\
& 1 \text {, } \\
& 3 \text {, } \\
& 1 \\
& 1 \text { " } \\
& 4
\end{aligned}
$$

Operations on extremities-

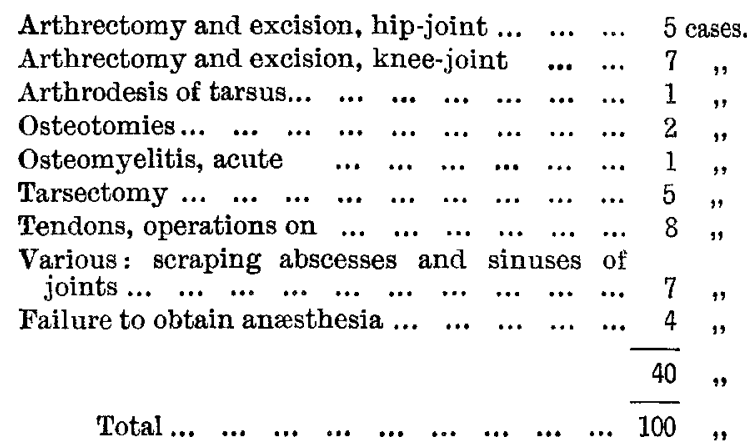

The first of these failures was in the case of a child, aged two and a half years, suffering from lumbar abscess due to spinal caries. The curvature was situated in the lumbar region and the puncture was made below the obvious seat of disease, as I was anxious to determine whether spinal anæsthesia was contra-indicated in such cases. Two injections failed to produce any anæsthesia at all. There is no question that the needle was in the theca. In another case of lumbar caries with psoas abscesses the first injection could not be made to ascend high enough for satisfactory anæsthesia, in spite of the adoption of the exaggerated high pelvis position. It was only after waiting a considerable time and with difficulty that the second dose was satisfactory. (There was one further failure in a case of the same class in my second series. On this occasion the perineum only could be anæsthetised.) It seems fair to conclude, therefore, that children with any spinal caries are unsuitable for spinal anæsthesia, even when the puncture can be made through a healthy part; and the same should hold true for children who have recovered from posterior basic meningitis, for in these patients adhesions within the spinal theca are commonly encountered, so that anomalous effects would in all probability result. The three other failures all occurred together, and with the same box of stovaine. The first two of these were both submitted to general anæsthesia although the second of them had had a successful spinal anæsthetic only four days previously. The third case I sent back to bed until the following day when I repeated the attempt with a new box of stovaine; a perfect anæsthesia of an hour's duration resulted from the firstinjection of the same quantity of solution as that given on the previous day. These failures must be attributed to the fact that the stovaine had been kept too long by the makers and lost its potency, for the last case had tingling sensations in 
the feet which never amounted to anæsthesia; they can hardly, I think, be attributed to faulty technique in view of the foregoing facts, especially when we know how the drug loses its value with keeping. General anæsthesia was therefore administered in three out of 100 cases where spinal anæsthesia had failed. In two other cases a whiff of chloroform was used at the end of the spinal anæsthesia when the effects of the stovaine began to wear off, in one case for the skin sutures and in the other for the termination of the operation also. Apart, therefore, from the case with spinal disease on one occasion and the defective quality of the stovaine on the other, there has been no failure in the first series.

Dosage.-The amount of stovaine administered in each case has been more or less proportionate to the age of the patient, the length of the operation, and the level of anæsthesia required. A study of the tables, by means of which a record of each case has been kept, shows how far definite statements can at present be made. As regards the level to which the paralysis is required to ascend, it can be definitely stated that if the puncture be always made in the same intervertebral space the dose must be proportionately increased for a high level and may be similarly decreased for a low level of anæsthesia. For example, if a puncture be made between the third and fourth lumbar spines and anæsthesia of the foot is required, 1 cubic centimetre (or 2.5 centigrammes of stovaine) would in a child of six years produce complete paralysis for one hour. The same dose, however, if the pelvis be appropriately raised would only paralyse the upper abdomen for 45 minutes. In other words, the higher the fluid ascends the smaller is the amount of it which reaches the nerve roots, and therefore to induce paralysis to a high level (for example, in abdominal work above the umbilicus) three points must be remembered: (1) to employ a larger dose of stovaine ; (2) to puncture in a higher intervertebral space; and (3) to use the high pelvic position immediately the injection has been given, always remembering to keep the shoulders raised a little.

Chaput ${ }^{13}$ emphasises the important relation of the dose to the height of the anæsthesia. In producing high anæsthesia it should further be borne in mind that above the area of absolute anæsthesia is a zone, of varying extent, of relative anæsthesia which I have known to extend over the scalp. Thus it is seen the anæsthesia lasts longer below than above, and it is also true that the onset is from below upwards, while the recovery takes place from above downwards, muscular power returning before sensation.

I cannot, however, think it right ever to make the puncture above the interspace between the first and second lumbar vertebræ, though this practice is adopted by some surgeons as a routine (Avramesco ${ }^{14}$ ). This author punctures between: (1) the third and fourth lumbar spines for operations on the perineum, external genitals and anus; (2) the first and second lumbar spines for operations on the inguinal region and lower extremities; (3) the ninth and tenth dorsal spines for operations on the abdomen below the umbilicus; and (4) the sixth and seventh dorsal spines for operations on the abdomen above the umbilicus. I have found the interval between the third and fourth lumbar spines the most suitable site for puncturing in routine cases and enter the needle above or below the level according as a higher or lower paralysis is required.

The Relation of the Dose of Stovaine to the Length of Ancesthesiu Produced.

TABLE III.

A.-Age Six Months and Under.

\begin{tabular}{c|c|c|c}
\hline Dose. & $\begin{array}{c}\text { No. of } \\
\text { cases. }\end{array}$ & $\begin{array}{c}\text { Recovery } \\
\text { not stated. }\end{array}$ & Recovery. \\
\hline $2 / 5$ c.c. & 1 & 1 & - \\
$2 \frac{1}{2} / 5$ c.c. & 3 & 1 & $\begin{array}{c}\text { 1 hour. } \\
\text { Over 1 hour. }\end{array}$ \\
\hline $3 / 5$ c.c. & 1 & - & Over 1 hour. \\
\hline $\begin{array}{c}\text { Arerage } \frac{21 / 2}{5} \text { c.c. } \\
\text { i.e., } 0012 \text { grm. } \\
\text { stovaine. }\end{array}$ & 5 & 2 & \\
\hline
\end{tabular}

13 Société de Chirurgie de Paris, Oct. 12th, 1904.

It Avramesco: Revue Neurologique. THE LÁNCE's, 1901, vol. i., p. 637 .
B. - From Six Months to 1 Tear.

$3 / 5$ c.c. was administered to all but one child who had $3 / 5$ c.c. and $4 / 5$ c.c. in consecutive doses. Fach of these produced anæsthessia for three-quarters of an hour. Rest varied from-

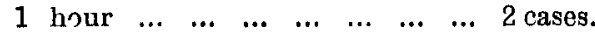

$$
\begin{aligned}
& \begin{array}{llllllllllll}
1 \frac{1}{4} & , & \ldots & \ldots & \ldots & \ldots & \ldots & \ldots & \ldots & \ldots & 3 & ,
\end{array}
\end{aligned}
$$

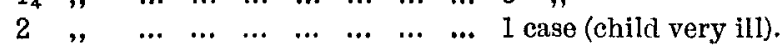

$$
\begin{aligned}
& \text { Average : } 3 / 5 \text { c.c.-i.e., } 0.015 \mathrm{grm} \text {. stovaine. } \\
& \text { Average time; } 1 \text { hour } 10 \text { minutes. }
\end{aligned}
$$$$
\text { C.-From } 1 \text { to } 2 \text { Iears. }
$$

\begin{tabular}{|c|c|c|c|}
\hline \multicolumn{4}{|c|}{ D. -From 2 to 5 Years. } \\
\hline Dose. & $\begin{array}{l}\text { No. of } \\
\text { cases. }\end{array}$ & $\begin{array}{c}\text { Recovery } \\
\text { not stated. }\end{array}$ & Recovery. \\
\hline $\begin{array}{c}3 / 5 \text { c.c. }=0.015 \mathrm{grm} . \\
\text { stovaine. }\end{array}$ & 3 & 0 & $\begin{array}{l}1 \text { case, } 30 \mathrm{~min} . \\
2 \text { cases, } 40 \text { ", } \\
\text { Average } 36 \text { ", }\end{array}$ \\
\hline $\begin{array}{c}4 / 5 \text { c.c. }=0.02 \mathrm{grm} . \\
\text { stovaine. }\end{array}$ & 12 & 4 & $\begin{array}{l}1 \text { case, } 1 \frac{1}{2} \text { hour. } \\
4 \text { cases, } 1 \text { ", } \\
3 \text { cases, } \frac{1}{2} \text { " } \\
\text { Average } 55 \text { min. }\end{array}$ \\
\hline $\begin{array}{c}5 / 5 \text { c.c. }=0.025 \mathrm{grm} . \\
\text { stovaine. }\end{array}$ & 3 & 0 & $\begin{array}{l}1 \text { case, } 1 \frac{1}{4} \text { hour. } \\
1 \text { case, } 1 \text { ", } \\
1 \text { case, } 1 \frac{1}{2}, " \\
\text { Average } 1 \frac{1}{4}, "\end{array}$ \\
\hline $5 \frac{\mathrm{l}}{2} / 5$ c.c. & 1 & 0 & $1 \frac{1}{4}$ hour \\
\hline $\begin{array}{c}6 / 5 \text { c.c. }=0.03 \mathrm{grm} . \\
\text { stovaine. }\end{array}$ & 3 & 0 & $\begin{array}{l}2 \text { cases, } 1 \text { hour } 10 \text { min. } \\
1 \text { case, } 1 \text { hour. } \\
\text { Average over } 1 \text { hour. }\end{array}$ \\
\hline $\begin{array}{c}8 / 5 \text { c.c. }=0.04 \mathrm{grm} . \\
\text { stovaine. }\end{array}$ & 1 & 0 & $\begin{array}{l}1 \text { hour (given in } 2 \\
\text { separate doses; case of } \\
\text { spinal caries). }\end{array}$ \\
\hline
\end{tabular}

\begin{tabular}{|c|c|c|c}
\hline Dose. & $\begin{array}{c}\text { No. of } \\
\text { cases. }\end{array}$ & $\begin{array}{c}\text { Recovery } \\
\text { not stated. }\end{array}$ & Recovery. \\
\hline $\begin{array}{c}\text { 3/5 c.c. }=0.015 \text { grm. } \\
\text { stovaine. }\end{array}$ & 7 & 0 & $\begin{array}{l}\text { Lowest } \frac{1}{2} \text { hour. } \\
\text { Highest } 1 \frac{1}{2} \text { hour. } \\
\text { Average over } 1 \text { hour. }\end{array}$ \\
$\begin{array}{c}4 / 5 \text { c.c. }=0.02 \text { grm. } \\
\text { stovaine. }\end{array}$ & 5 & $\begin{array}{c}\text { Said to be } \\
2 \frac{1}{2} \text { lours in } \\
\text { one case } \\
\text { (omitted) }\end{array}$ & 3 cases, 1 hour. \\
\hline
\end{tabular}

\begin{tabular}{|c|c|c|c|}
\hline Dose. & $\begin{array}{l}\text { No. of } \\
\text { cases. }\end{array}$ & $\begin{array}{l}\text { Recovery } \\
\text { not stated. }\end{array}$ & Recovery. \\
\hline $\begin{array}{c}3 / 5 \text { c.c. }=0.015 \mathrm{grm} . \\
\text { stovaine. }\end{array}$ & 1 & 1 & - \\
\hline $\begin{array}{c}4 / 5 \text { c.c. }=0.02 \text { grm. } \\
\text { stovaine. }\end{array}$ & 2 & 0 & $\begin{array}{l}1 \text { case, } 1 \frac{1}{4} \text { hour. } \\
1 \text { case, } 1 \text { hour } 10 \mathrm{~min} . \\
\text { Average } 1 \frac{1}{4} \text { hour. }\end{array}$ \\
\hline $\begin{array}{c}5 / 5 \text { c.c. }=0.025 \text { grm. } \\
\text { stovaine. }\end{array}$ & 10 & 1 & $\begin{array}{l}3 \text { cases, } 1 \text { hour. } \\
3 \text { cases, } 1 \frac{1}{4} \text {," } \\
1 \text { case, } 50 \text { min. } \\
1 \text { case, } 45 \text { ", } \\
1 \text { case, } 50 \text { ", } \\
\text { Average } 1 \text { hour. }\end{array}$ \\
\hline $\begin{array}{c}6 / 5 \text { c.c. }=0.03 \mathrm{grm} . \\
\text { stovaine. }\end{array}$ & 23 & 5 & $\begin{array}{l}3 \text { cases, } 40 \text { min. } \\
6 \text { cases, } 1 \text { hour. } \\
5 \text { cases, } 1 \frac{1}{4}, " \text { and over. } \\
4 \text { cases, } 1 \frac{1}{2} \text { " and } \\
\text { Average } 1 \frac{1}{4} \text { hour. }\end{array}$ \\
\hline $\begin{array}{c}6 \frac{1}{2} / 5 \text { and } 7 / 5 \text { c.c. }= \\
0.035 \text { grm. } \\
\text { stovaine. }\end{array}$ & 7 & 1 & $\begin{array}{l}3 \text { cases, } 1 \text { hour. } \\
2 \text { cases, } 1_{\frac{1}{2}}, " \\
1 \text { case, } 1 \frac{1}{4}, " \\
\text { A verage } 1_{\frac{1}{4}}, "\end{array}$ \\
\hline $\begin{array}{c}7 \frac{1}{\mathbf{4}} / 5 \text { and } 85 \text { c.c. }= \\
0.04 \text { grm. } \\
\text { stovaine. }\end{array}$ & 4 & 1 & $\begin{array}{l}1 \text { case, } \frac{1}{4} \text { hour. } \\
1 \text { case, } 1 \frac{1}{4}, " \\
1 \text { case, } 1 \frac{1}{2} \text { " } \\
\text { Average } 1 \text { hour } 10 \mathrm{~min} .\end{array}$ \\
\hline
\end{tabular}

E. - From 5 to 12 Years.

A study of Table III., sections A, B, C, D, and E, shows how far the quantity of the drug administered bears any direct relation to the length of time the paralysis lasts. The estimation of the time after injection at which recovery ensues is open to a great many fallacies, and, in routine hospital work, when the return of sensation and movement was noted by many different sisters and nurses in the wards, any great degree of accuracy could not be expected. For purposes of comparison the same routine was followed in all cases - the return of power was indicated by the presence of movement in the whole of the lower limbs, and the return of sensation tested by the response to the prick of a pin. 
Without recapitulating the facts set forth in the accompanying tables, these, I think, bring to light several points worthy of notice. 1. There is a certain variability, within limits, in the length of anæsthesia produced by a given dose in several patients of the same age. 2. In a series of cases the length of anæsthesia is in direct relation to the amount of the drug injected, but only within certain limits. 3. The surgeon may depend on from three-quarters to one hour of operable anæsthesia. A comparison of the different items in each section and of similar items in the different sections of Table III. will confirm these statements.

The question arises as to the reasons for the variability of the effects of the same dose in similar patients. This variability will be found to depend on several facts: (1) the technique of administration - a greater uniformity has been obtained with increased familiarity with the methods adopted; (2) the bulk of fluid, the strength, and probably the nature of the drug employed; and (3) certain factors unknown, or at least problematical, to which I shail refer in the study of my second series of cases. In all but seven cases operable anæsthesia was present within five minutes of the injection though anæsthesia was not usually complete until from eight to ten minutes. For example, the presence of some muscular power or sensation to heat and cold does not hamper the commencement of an operation, and these disappear after painful sensation. In one instance excision of the knee-joint was done under spinal anæsthesia, and no part of the operation, including the sawing of the bones, was felt by the patient; when, however, during the progress of the operation, hot saline was poured over the wound he screamed, "You're burning me." of the seven cases in which the commencement of the operation had to be delayed for more than five minutes in three the time was 7, 8, and 15 minutes respectively; the last case had extreme scoliosis and there may have been some error in the technique of the injection to account for the delay. In infants under two years the delay tends to be less, for many of these have been paralysed in one or two minutes. I have made it a rule that if no paralysis has supervened in ten minutes after the injection a second dose should be given as the fluid has not reached the subarachnoid space.

The approximate amount of cerebro-spinal fuid withdran'n before the injection of stovaine has been recorded in the majority of cases, though actual measurements were only taken in a few. The reports are sufficiently accurate to determine whether there is any advantage or disadvantage in withdrawing a fair quantity. 1. As regards the general condition of the child, the most careful analysis of the tables has failed to detect any change attributable to the withdrawal of three or four drachms of cerebro-spinal fluid previous to injection of stovaine. 2. The influence of withdrawing this amount on the course of the anæsthesia deserves a word. A study of the tables gives no definite information on this point; indeed, it could not be conclusive where there are clearly so many other factors at work. My own impression, however, is that the withdrawal of two or three drachms of cerebro-spinal fluid previous to giving the injection tends to prolong the anæsthesia, and I now always adopt this procedure. In this connexion it is interesting to note that $\mathrm{Mr}$. Dean ${ }^{15}$ considers that the sudden diminution of cerebrospinal pressure may be responsible for the lesions of the ocular nerves (especially the sixth) which have occasionally been reported as occurring after spinal anæsthesia. This view receives no support from my series of cases. Headache also might presumably be attributed to the same causes, but without any evidence, so far as I can ascertain. Mr. Dean, however, states that the withdrawal of some cerebro-spinal fluid increases the certainty of the anæsthesia.

Extent of the ancesthesia. -If the table of operations be reviewed it will be seen that these embrace a considerable variety of cases. For the older children the paralysis may be approximately limited according to necessity, but for infants and smaller children it has been found advisable to paralyse to the costal margin or at least the umbilicus in the majority of cases, and for abdominal work to between the costal margin and the nipples. In hernias also it is advisable to induce paralysis to the costal margin, for it may be necessary to ligature omentum; more than once this operation has been performed under a low anæsthesia, all sensation being absent until the omentum was ligatured, when the child cried out with pain. In operations involving the alteration of the patient's position it is advisable to preserve, as far as possible, the original posture, though a deviation from this will not influence materially the course of the anæs. thesia. In operations on the tendons of spastic cases spinal anæsthesia is not suitable, for the complete muscular flaccidity obtained increases the difficulty of estimating the amount of lengthening necessary. Heart disease, if compensated, is no contraindication to the use of stovaine, and I have had no experience in uncompensated cases. In cases of suppuration in the upper abdomen and under the diaphragm it must be remembered that the action of this muscle is probably hampered (the same holds true in cases of great abdominal distension). Care must therefore be taken to paralyse the intercostal muscles as little as possible. For this reason I am sure it is quite unjustifiable to operate within the thorax, in cases of empyema, pyopericarditis, \&c., under spinal anæsthesia, and no such operations have been performed in my series. This anæsthesia, however, has been frequently employed for these operations both in this country and on the continent.

I now propose to consider briefly the complications and sequelæ noted in this series of cases.

1. Vomiting may occur while under the influence of the anæsthesia or after recovery has taken place. 30 cases out of the hundred either vomited or retched during the opera. tion or after recovery from the anæsthesia. These vomits were usually copious and occurred between 10 and 20 minutes after the injection (usually about 15 minutes). The attack, without exception, passed off in less than five minutes, and rarely lasted more than a minute or two in the majority of cases. Of these 30 cases :-

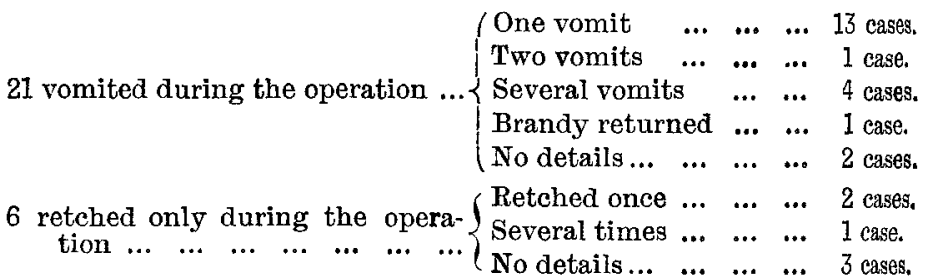
$\left\{\begin{array}{l}\text { One an infant of } 8 \text { months (re- } \\ \text { section of intestine). Vomiting }\end{array}\right.$ preceded death 4 hours later. The other case had slight vomiting 10 hours later.

1 complained of nausea during the operation.

$$
\begin{array}{lllllll}
\text { Total } & \ldots & \ldots & \ldots & \ldots & \ldots & 30 \text { cases. }
\end{array}
$$

Of these 30 cases five were suffering from acute abdominal disease (four being under one year old), and in them vomit. ing was, to some extent at least, a symptom of the disease; in one case, however, the anæsthesia was not given high enough and vomiting ensued on manipulation of the transverse colon. This leaves us, therefore, with 25 per cent. of the children in whom the vomiting was clearly due to the anæsthesia. Sex is not a determining factor, but the younger the child the less is the tendency to vomit. I have been unable to satisfy myself that a more careful regulation of the dose by the age of the patient can control this unpleasant manifestation.

2. Following on this symptom a certain degree of pallor supervened with a little sinking under the eyes and accompanied by a slight fall of pulse tension and slowing of the respiration. This occurred in nearly all the children in the series. In 14 instances it was noted that the pallor was very marked and accompanied by sweating. The rate of the pulse was seldom altered to any extent. I have reported these symptoms in some detail because in the study of $\mathrm{my}$ second 100 cases $I$ hope to investigate their causation and prevention; but in no case were these changes ever sufficient to cause any anxiety or hamper the course of the operation.

3. In some instances where nausea or vomiting was absent a transitory restlessness was noted as preceding the onset of pallor. This restlessness occurred in 10 per cent. of cases, all of which were males :-

$$
\begin{aligned}
& \begin{array}{llllll}
\text { Under } 2 \text { years } & \ldots & \ldots & \ldots & \ldots & 2 \text { cases }
\end{array}
\end{aligned}
$$

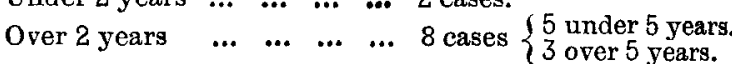

These symptoms, unpleasant but never serious, are quite readily amenable to a dose of brandy, which rapidly restores the colour in all but the very marked cases. Their occurrence cannot be predicted in any given case, and is not influenced 
to any extent by withholding food before or during the operation. There is, however, less tendency to vomit if the stomach is empty. Chaput ${ }^{16}$ has experienced these inconveniences in the employment of rachistovainization, and his opinion of their severity is summed up in the following words: "Pour ma part, les faits de Leguen ne modifièrent pas mon opinion sur la valeur de la méthode de Tuffier, et $\mathrm{je}$ continuai à en rester partisan malgré quelques petits in. convénients sans aucune importance."

Sequela.-There has been no case of incontinence, persistent paralysis, ophthalmoplegia, tremors, convulsions, or epileptic fits ${ }^{17}$ in the series. Slight headache, lasting for a few hours, was complained of in two cases, while in no case has death resulted from the anæsthesia. The majority of these sequelæ have been reported from the continent, and it seems significant that in many instances there has been a remarkably strong family or personal history of nervous and mental disease. Ocular palsy is reported in one case from simple puncture without the injection of any anæsthetic. ${ }^{18}$ In this connexion Mingazzini's case is particularly interesting and I would refer the reader to this paper. 74 children were examined, or information concerning them was obtained in writing, from one to six months after the anæsthesia; no answer was received in eight instances. Nine children died subsequently from the disease for which they were operated on, and when a necropsy was performed no abnormality was detected in the nerve roots, the cord, or its membranes. One child had spinal anæsthesia on three, and three children on two, occasions. These, together with the four failures, make up the tutal of 100 cases.

The advantages to be gained by the use of spinal anæsthesia have so far impressed me that I am convinced it will occupy an important place in the surgery of children in the future. Such disadrantages as are consequent on its use will doubtless be eliminated as more work is done on the subject, but these I bave found comparatively trifling when compared with those of general anæsthesia administered under the same conditions. A detailed consideration of these advantages is better deferred until after a review of the second series of cases, for a considerably wider range of operative work will thus be embraced.

(To be continued.)

\section{A CASE OF ACUTE TORSION OF A WANDERING SPLEEN ; SPLENEC- TOMY; RECOVERY.}

BY IAN MACDONALD, M.D. EdIN. AND PARIS, - CONSULTLNG SURgEON TO THE UNITED ALKALI, PEÑA AND ESPERANZa COMPANIES; AND

W. A. MACKAY, M.D. EDIN., F.R.C.S. EDIN., CONSULTING SURGEON TO THE RIO TINTO AND UNITED ALKALI COMPANIES.

THoUGH all the viscera except the liver, and almost every variety of abdominal tumour are liable to torsion of the pedicle, the accident in the spleen is rare. For in a series of 708 splenectomies performed up to date, and collected and analysed by Johnson ${ }^{1}$ in connexion with six cases operated on by him, only 39 showed twisting of the pedicle; of these 27 were idiopathic enlargements of the spleen and only 12 malarial. From Johnson's table it appears that splenectomy of the malarial spleen with torsion has been performed 12 times, with ten recoveries and two deaths. The mortality in this condition shows steady diminution, for before 1890 two cases were reported with one death, from 1890 to 1900 three cases with one death, and since 1900 seven cases without a death.

Wandering spleen is a rare affection, and it occurs far more frequently in women than in men. During a long residence in South Spain, where malaria is the most common disease, many cases of hypertrophied malarial spleen have

16 Loc. cit.

17 Loeffler: Munchener Medicinische Wochenschrift 1906, p. 95

18 Loeffler : Loc. cit. Hesse: Deutsche Medicinische Wochenschrift, 1907, p. 1491. Wolff: Berliner Klinische Wochenschrift, vol, xliv., 1907, p. 1305. Mingazzini : Revue Neurologique, March 15th, 1908,
185.

I Annals of Surgery, vol, xlviii., No. 1, July, 1908. passed through our hands, but the case we record here is the first we have met of wandering spleen. The length of the pedicle may be such that the displaced organ may occupy any region of the abdomen, and probably no other viscus has given rise to more erroneous diagnosis. In the quiescent state the errant spleen has been mistaken for ovarian and uterine tumours, and in the acutely turgid condition consequent on torsion of its pedicle it has simulated abscesses in the subphrenic and perigastric regions. ${ }^{2}$ In the following case it was mistaken for a mobile kidney, as it lay to the right of the umbilicus, and later, when torsion was acute and the congested, enormously enlarged organ filled the right iliac fossa, to those who saw it then for the first time the picture of appendicitis seemed complete.

Kadygroboff ${ }^{3}$ states that the diagnosis of mobile spleen is difficult, and more so that of torsion of its pedicle; in fact, he says that it has never yet been diagnosed, adding that the diagnosis should not present much difficulty were the existence of a wandering spleen already known. But an interesting case reported by Bland-Sutton ${ }^{*}$ in 1892 shows that the condition has been recognised. This surgeon in a case of illdefined tumour narrowed down the primary diagnosis to that of wandering spleen or omental hydatid. On operating he found a wandering spleen with one and a half turns on its pedicle which he straightened out, replacing the spleen in the left hypochondrium. Three and a half months later symptoms of acute torsion appeared, which, he remarks, were exactly those met with in acute axial rotation of ovarian tumours, and a second operation became urgent. The spleen, lying in the pelvis with three complete twists of its pedicle, was removed, the patient, a woman 22 years of age, making a rapid recovery. He further remarks that the shallowness of the notch on the anterior border explained why the definite diagnosis of splenic tumour was not made before the first operation.

We have no real knowledge as to the cause of torsion, though many theories have been advanced. In this case there had been an accouchement eight months previously, which is considered a predisposing cause (Laveran). The pathological conditions which follow torsion are well known - the formation of infarcts from the acute congestion of the organ, thrombosis of the vessels, possibility of rupture, with grave intraperitoneal hæmorrhage or even necrosis if the torsion is tight. Bland-Sutton and Pozzi ${ }^{5}$ record cases where evidently torsion of the pedicle has resulted in complete detachment of the organ, for in two cases of obscure pelvic tumours histological examination revealed splenic tissue. Usually the twisting is limited to three turns of a spiral, though Kadygroboff reports a case where four existed ; the following case only showed two. Clinically, Kadygroboff describes three types of this torsion, which, however, are not very clearly separated from one another: an acute form with all the characters of an acute peritonitis; a subacute type where the spleen, much increased in size, is tense and painful to palpation, shows bæmorrhagic infarcts, and is liable to secondary infections; and a chronic variety which develops almost without symptoms. Whichever type is present there is always considerable irritation of the neighbouring peritoneum and the gravest complications may occur, such as intestinal obstruction (Rydygier) or even necrosis of the fundus of the stomach from distensiun and obliteration of the vessels (Govseieff). The extent to which the peritoneum is involved varies greatly, and Hartmann, ${ }^{6}$ in connexion with a case of acute torsion among four of wandering spleen, has called attention to the fact that the peritonitis, on removal of the tumour, rapidly disappears without flushing or drainage of the abdominal cavity. He considers the peritonitis aseptic.

The history of our case is as follows:-

A woman, a multipara, 23 years of age, was seen by one of us in a Spanish village in consultation with her usual medical attendant a month previously. She was a delicate, anæmic subject, evidently a chronic paludic, and was nursing a child eight months old. She complained of colicky pains and nausea, with marked frequency of urinating. The first attack came on one month after the birth of the child and

2 Moynihan : Abdominal Operations, p. 652 3 Journal de Chirurgie, April, 1908

Transactions of the Clinical Society of Lendon, vol. xxvi., p. 46 Surgery of Diseases of the Ovaries and Tubes, p. 165; Nine Cases of Splenectomy, The LaNOET, Dec. 1st, 1900. p. 1578.

Revue de Chirurgie, vol, xxviii., p. 405.

6 Congrès Francais de Chirurgie, 1895, p. 495. 